Copyright $\odot 2018$ The Author(s). Published by BCS, The Chartered Institute for IT under Creative Commons license http://creativecommons.org/ licenses/by/4.0/

\section{In this issue - patient risks are ignored at organisation level}

\author{
Simon de Lusignan \\ Professor, Primary Care and Clinical Informatics, University of Surrey, UK \\ Editor-in-Chief Journal of Innovation in Health Informatics
}

Keywords: medical records systems, computerised, patients, risk, risk management, health care economics and organizations

\section{INTRODUCTION AND EDITOR'S CHOICE}

The paper we publish by Mark-Alexander Sujan is timely. ${ }^{1}$ We publish his recommendations for managing patient safety risks, in a week, when a report was published setting out how there are estimated to be 237 million medication errors that occur at some point in the medication process in England per year. Of these errors, 66 million (28\%) errors are thought to be clinically significant. ${ }^{2}$ Sujan makes three key recommendations:

1) Focus on organisational learning

2) Promote proactive risk management

3) Make risk management decisions transparent and explicit

He recommends bottom-up innovation alongside implementation of little-known standards as the way forward.

\section{BAWA-GARBA EDITORIAL - CALL FOR ACTION TO THE HEALTH AND CARE INFORMATICS COMMUNITY}

The Editorial in this issue calls for the informatics community to think what systems could so easily have been in place that might have reduced the chance of such a tragedy occurring; we appear not to have learnt lessons known for many years. ${ }^{3}$ Laurence Weed not only developed problem-oriented medical records (POMR), but also computerised them. His computerised system: problem-oriented medical information system (PROMIS) was ahead of its time. ${ }^{4}$

Box 1 Weed's first computerised medical record (CMR) system (from Wright et al.) ${ }^{4}$

PROMIS was the first clinical information system to use a touch screen terminal. PROMIS was driven by a large medical knowledge base that was initially developed by Dr Weed and his wife Laura Weed ${ }^{1}$ and later by a team of clinicians, librarians and systems analysts. PROMIS was organised entirely around the POMR concept, with the nurse beginning to populate the database, followed by the patient, who would complete a 275-question review-of-systems. Medical students and residents then added additional information, and documented a physical exam - all in structured form. Once the database was populated, the problem list was constructed, plans were developed and progress notes developed. The knowledge base required to support all of these modules was vast, and eventually specialists were brought in to extend it. 


\section{IMPLEMENTATION AND INTEGRATION INTO CLINICAL WORKFLOW}

Implementation and integration of telemedicine into clinical workflow has long been a challenge. Your editor was involved in a controlled telemedicine pilot back in the last century! Honest! ${ }^{5,6}$ Even when the technology was offered to the NHS free - there was no interest from our local commissioners! The paper by Reed et al. ${ }^{7}$ reminds us that corporate culture and the skills to implement technology are as much needed now as they were 20 years ago! Perhaps even more so, as the technology is so much smarter.

\section{CHILD HEALTH}

A paper by Carsley et al. sets out to report completeness of data about obesity in childhood records. They found that over $90 \%$ of records had valid information about their Canadian network. ${ }^{8}$ My sense is that the completeness of data in computerised medical records is improving over time, and with obesity, such an international problem having data about complete cohorts is really valuable.

\section{A GOOD THEORETICAL BASIS WILL STRENGTHEN OUR DISCIPLINE!}

Don't let mention of Q-methodologies, technology acceptance model (TAM) or unified theory of acceptance and use of technology (UTAUT) put you off an excellent article by Ladan et al. ${ }^{9}$ To start with let me give each of the above a brief explanation:

- Q-methodology (also called Q-sort) is the systematic study of participant viewpoints. It is a key element of many evaluations. Multiple participant opinions might be ranked (the $\mathrm{Q}$-sort) into those that area are most important.

\section{REFERENCES}

1. Sujan. Managing health IT risks: reflections. Journal of Innovation in Health Informatics 2018;25(1):7-13. doi: 10.14236/jhi.v25i1.952.

2. Elliott R, Camacho E, Campbell F, Jankovic D, Martyn St James $\mathrm{M}$, Kaltenthaler $\mathrm{E}$, et al. Prevalence and economic burden of medication errors in the NHS in England. In: Rapid evidence synthesis and economic analysis of the prevalence and burden of medication error in the UK. 2018. Policy Research Unit in Economic Evaluation of Health and Care Interventions. Universities of Sheffield and York. Available from: http://www.eepru.org.uk/ wp-content/uploads/2018/02/medication-error-report-revisedfinal.2-22022018.pdf.

3. de Lusignan S. Computerised medical record systems that guide and protect-reflections on the Bawa-Garba case. Journal of Innovation in Health Informatics 2018;25(1):58-59. doi: 10.14236/jhi.v25i1.1040.

4. Wright A, Sittig DF, McGowan J, Ash JS and Weed LL. Bringing science to medicine: an interview with Larry Weed, inventor of the problem-oriented medical record. Journal of the American Medical Informatics Association 2014;21(6):964-8. doi: 10.1136/amiajnl-2014-002776.

5. de Lusignan S, Meredith K, Wells S, Leatham E and Johnson P. A controlled pilot study in the use of telemedicine in the
- TAM - explores how two constructs: (1) Usefulness and (2) Ease of use often determine if a technology is used.

- UTAUT - is more complex and has four constructs (1) Users expectation about performance; (2) The effort required; (3) Social influences; and (4) What support there is.

The article explores these theories. Jump to Figures 1 and 2 in the paper by Ladan et al. ${ }^{9}$ to see how TAM and UTAUT are set out diagrammatically; then Figure 4, where they draw things together. As informatics develops as a discipline, we need to strengthen our theoretical underpinnings and define our core theory. This will add rigour to our discipline and its research. ${ }^{10}$

\section{ROBOT WARD ROUNDS COMING SOON!}

We report the findings from the comparative use of a robot (mobile, eye level and video-linked) that substituted for the surgeon on the ward round. This had good user and patient acceptance. ${ }^{11}$ (Though did not use Q-methodology, TAM or UTAUT!).

\section{LEARNING HEALTH SYSTEM AND STUDY PROTOCOL USING MIXED METHODS}

We publish an interesting letter calling for better development and theoretical underpinning of the learning health system (LHS). ${ }^{12}$ This letter is pertinent to our first paper which includes the call to focus on organisational learning to reduce risk. ${ }^{1}$ An effective LHS might know how to implement telemedicine too! ${ }^{5}$ Finally, Wiggins et al. ${ }^{13}$ present a protocol of how to undertake a mixed methods assessment of a decision support tool to improve decision making around a mother's choice of place of birth.

community on the management of heart failure-a report of the first three months. Studies in Health Technology and Informatics 1999;64:126-37.

6. de Lusignan S, Wells S, Johnson P, Meredith K and Leatham E. Compliance and effectiveness of 1 year's home telemonitoring. The report of a pilot study of patients with chronic heart failure. European Journal of Heart Failure 2001;3(6):723-30.

7. Freed J, Lowe C, Flodgren G, Binks R, Doughty K and Kolsi J. Telemedicine: is it really worth it? Journal of Innovation in Health Informatics 2018;25(1):14-18. doi: 10.14236/jhi.v25i1.957.

8. Carsley S, Birken CS, Parkin PC, Pullenayegum E and Tu K. Completeness and accuracy of anthropometric measurements in electronic medical records for children attending primary care. Journal of Innovation in Health Informatics 2018;25(1):19-26. doi:10.14236/jhi.v25i1.963.

9. Ladan MA, Wharrad $\mathrm{H}$ and Windle $\mathrm{R}$. Towards understanding healthcare professionals' adoption and use of technologies in clinical practice: using Q-methodology and models of technology acceptance. Journal of Innovation in Health Informatics 2018;25(1):27-37. doi: 10.14236/jhi.v25i1.965.

10. de Lusignan S, Barlow J and Scott PJ. Genesis of a UK Faculty of Clinical Informatics at a time of anticipation for some, and 
ruby, golden and diamond celebrations for others. Journal of Innovation in Health Informatics 2018;24(4):344-6. doi: 10.14236/jhi.v24i4.1003.

11. Croghan SM, Carroll P, Ridgway PF, Gillis AE and Reade S. Robot assisted surgical ward rounds. Journal of Innovation in Health Informatics 2018;25(1):41-56. doi: 10.14236/jhi. v25i1.982.

12. McLachlan S, Dube K, Buchanan D, Lean S, Johnson O, Potts $\mathrm{H}$, et al. Learning health systems: the research. Journal of Innovation in Health Informatics 2018;25(1):38-40. doi: 10.14236/jhi.v25i1.981.

13. Wiggins D, Hundley VA, Wilkins $C$, Bond $C$ and Walton $G$. The effect of a birthplace decision support tool on women's decision-making and information gathering behaviours during pregnancy: Mybirthplace study protocol. Journal of Innovation in Health Informatics 2018;25(1):1-6. doi: 10.14236/jhi.v25i1.945. 